\title{
Problems with Traditional Music and Its Current Appeal in Central Thailand
}

\author{
Thipsuda Imjai ${ }^{1}$, Ying Keeratiburana ${ }^{1} \&$ Marisa Koseyayothin ${ }^{2}$ \\ ${ }^{1}$ The Faculty of Cultural Science, Mahasarakham University, Khamriang Sub-District, Kantarawichai District, \\ Maha Sarakham Province, Thailand \\ ${ }^{2}$ Kanchanapisek Non-Formal Education Centre (Royal Academy), Salaya Sub-District, Bhuttamonthon District, \\ Nakhon Pathom Province, Thailand \\ Correspondence: Thipsuda Imjai, The Faculty of Cultural Science, Mahasarakham University, Khamriang \\ Sub-District, Kantarawichai District, Maha Sarakham Province 44150, Thailand. E-mail: timjai130@gmail.com
}

\author{
Received: April 29, 2014 Accepted: May 29, 2014 Online Published: June 12, 2014 \\ doi:10.5539/ach.v6n2p146 URL: http://dx.doi.org/10.5539/ach.v6n2p146
}

\begin{abstract}
Traditional music is a rich part of local culture that reveals much about everyday life in Central Thai society. This qualitative research examines traditional music in five central provinces of Thailand. By using survey, interview, observation and focus group discussion, the investigation assesses the problems with traditional music and the reason for its appeal in local communities. The results show that traditional music in Central Thailand is in decline thanks to the influence of Western culture that is altering audience preferences. Additionally, there are few young people interested in continuing the art and there is a lack of government support in maintaining the traditions. The traditional music retains appeal in its link to the everyday lifestyle of Central Thai society, yet requires modernization in order to survive in the face of global challenges.
\end{abstract}

Keywords: globalization, inheritance, local society, Thailand, traditional music

\section{Introduction}

The traditional music of central Thailand is an important part of Thai cultural heritage that reveals the lifestyle of people living in the plains to the North of Bangkok. The area is Thailand's metaphorical rice bowl or land of plenty, given its suitability for agriculture. As in all agricultural societies, central Thai people must compete with the seasons and surrounding environment to earn a living. Inheritance of culture and entertainment from generation to generation is one method of maintaining spirit during times of hard work or hardship. Following the tough planting season and after harvesting has been completed, the people will rest and create ways to relax. So rice harvest music (pleng kiao kao), the kam ram kiew dance, the Thai circle dance (ram tone or ram wong), the ram teud teung dance and the klong yao dance have all been developed. These dances are all performed wearing local cultural costumes and to music played by instruments made from local materials. The traditional musical instruments include the klong yao (a long drum), klong thon (a goblet drum), ching (small thick cymbals), chab (flat cymbals), krab (a clapper) and mong (a hanging gong).

Traditional music is the tunes and melodies of local people. Traditional singing uses plain and simple language and often involves an exchange between males and females. It is usually sung during festivals and celebrations or incorporated into local working practices. A variety of Thai names have been assigned to its different forms, such as pleng chao ban, pleng peun ban, pleng peun mueang, pleng patipak and dontri peun ban. However, these terms all fall under the English language category of 'folk songs'. The traditional music of central Thailand has been inherited by process of mook-pa-ta. Mook-pa-ta is word of mouth transmission and memorization, with no written record. The key characteristics are the charming expressions, deep meanings and witty ripostes, despite the simplicity of the language. Folk songs are thus a part of cultural heritage that has been accumulated over many generations from the past to the present (Loh-ngeun, 2009, p.3). The songs are a form of social entertainment and some songs are even designed to unite and strengthen the social group. These songs are distinctive for their chorus singing parts and the circular arrangement of the singers. The songs that represent a gender exchange have developed as songs for stage performance and entertainment but were originally sung in general society, especially during the New Year and Songkran festivals. The singers require special abilities in memory, quickness of mind, verbal skill, creative thinking and harmony. Given these requirements, not all members of society were able to sing the songs, leading to a separation between performers and audience. The 
best singers became popular among the other villagers and people from other neighbourhoods. If people did not have a talent for singing, they would enroll with a teacher to develop their ability. When there was an event such as a remembrance or ordination ceremony and the host wanted entertainment, they would employ talented singers to perform. This inspired the creation of musical groups involving a skilled male and female singer, who were formed to seek employment at local events. Singing on private patios and temple courtyards evolved to stage performances with specific backgrounds. Local folk music thus developed from community singing to a stage-performance art and profession (Nawikamoon, 1984, pp.77-79).

Traditional music reveals the lifestyle and adaptation of the local people to their surrounding environment. For this reason, the traditional music of different communities is not the same. However, music in the Central region of Thailand has some common features. As Anek Nawikamoon (1984) has highlighted, there are three universal traits of folk songs. Firstly, the music must be a composition created and developed by people in the local community, who also participate in its performance or, at the very least, constitute its audience. This includes music of the fields, such as pleng kiao kao, pleng song fang and pleng pan fang. These folk songs were sung by rice farmers in the field, who developed the music by singing ripostes to other farmers. There is also a chorus to help maintain the rhythm of the song. Secondly, the majority of folk songs have flexible lyrics that can be adapted, expanded or reduced according to the wishes of the singer. The same song may be found on two separate occasions with two separate lyric sets. Thirdly, the folk music is uncomplicated. As the music was developed in the fields during work, the language used is short, simple and derives from the everyday vocabulary of farm workers. There is no need for many instruments as the songs were originally performed in the fields or on patios and temple courtyards. The addition of instruments is purely for maintaining the rhythm of the music. Backgrounds are not necessary and costumes are based on everyday clothing.

Aside from these three common traits, there are a number of characteristics for performers. The performers are enthusiastic and witty, with a skill in using language to satirize and insinuate from examples they have seen in their everyday experience. Local dialect is incorporated into the lyrics, which reveals otherwise concealed aspects of local lifestyle, customs and trends. Rhyming verses end with similar vowel endings, such as 'klon lai' where ending sounds are always a 'long i' and 'klon lee' where ending sounds are always a 'long e'. It is common for repetition in folk songs, such as in pleng pittan, pleng puang malai and pleng choi. The positives of repetition are that it allows people in the vicinity to participate in the music easily, creating a merry atmosphere (Patarachai, 2010). Specifically, traditional music in central Thailand is used for courting and contains many double-entendres, which reveal the light-hearted and playful nature of central Thai lifestyle. Ultimately, this is entertainment of the people, created by locals for locals.

Modern Thai society has been influenced by Western civilization, especially in the field of technology. This has affected national culture, in particular traditional performances because they have not adapted to meet the demands of changed society (Pongpaiboon, 1999). Those performances that have managed to survive have done so by modifying in line with modern trends (Maijaroen, 2009). Traditional music of central Thailand has declined in popularity and presence (Detpimon, 1988; Saihoo, 1980), yet continues to hold important value for Thai culture and economy. For this reason, the research team embarked upon a study to determine the specific problems with traditional music and its current appeal in the communities of Central Thailand.

\section{Literature Review}

Traditional music in Thailand derives from the working environment of ancestors and the search for entertainment (Sutchaya, 1982). The music has been inherited by today's society via mook-pa-ta, or the process of memorization from exposure (Subongkot, 1983). The music contains its own value and reveals a dual set of conditions: 1) feelings and thoughts of people, extrapolation of meaning, perspectives and concepts; 2) society and culture, such as popularities, lifestyle, occupations and communication. Somsak Srisantisuk and Suwan Buatuan (1985) studied the changing society and culture among indigenous groups in Kalasin Province. They found that the music of two communities with the same original traditions developed differently due to their location. If the music was in an area where it was influenced by external culture and society, the characteristics of the music altered to incorporate this influence (Srisantisuk \& Buatuan, 1985).

The traditional music of central Thailand has also been studied more specifically. Anek Nawikamoon and Manat Poonpon (1987) found that there were over forty types of traditional music in the region, of which many were only known in the local area and many more were only known in individual provinces. Others, such as pleng hey nang maew and pleng choi, were known regionally. Since the past, traditional music in central Thailand has provided a diverse range of benefits for society, both internally and externally. Pranee Wongtet (1990) spoke of five specific roles and functions of music for society: 1) music acts as a representative of 
symbolic systems in society, revealing religious beliefs and social classes; 2) music stimulates the senses and arouses people for battle, war and work; 3 ) music acts as a social control and helps to maintain social standards, while indicating appropriate regulations and behaviours; 4) music helps maintain important social institutions, such as religion and beliefs, ensuring that ceremonies have a purpose and identity; 5) music encourages the continuity and strength of culture.

Ee-saew is a folk song of Suphanburi Province and, by studying the song, Buapan Supanyot (1992) found that the problems and obstacles for its creation and inheritance come from the artists themselves and popularity within society. Conservation of the song to protect its inheritance is therefore necessary, yet current inheritance of traditional knowledge is primarily achieved by word of mouth, which can be unreliable (Saprasert, 1999). The Office of the National Education Commission (1998) found four methods for the inheritance of traditional knowledge in communities: 1) mouth to mouth inheritance between close family, friends and extended relatives; 2) group inheritance; 3 ) inheritance by participation; 4) inheritance by documentary study. Traditional music in central Thailand requires sharp wit (Waengwan, 1998) and currently needs to be developed privately because it is not expressly taught in academic institutions, which pay most attention to traditional knowledge surrounding beliefs and religion (Tongbut, 1999).

\section{Methodology}

This was a qualitative research conducted from January to August, 2012. Five provinces in central Thailand were purposively selected for this investigation: Suphanburi, Ang Thong, Kanchanaburi, Singburi and Lopburi. The sample group for the study was determined by a purposive sampling method and was composed of one hundred and twenty two individuals involved with the performances of five musical groups in the research area.

Research data was gathered by document analysis and field study. A variety of tools were used in the field, specifically survey, structured and unstructured interview, participant and non-participant observation and focus group discussion. The structured interview was divided into two parts. The first part was a set of questions designed to gather personal details from the respondents. The second part was a set of open ended questions designed to ask what the current conditions and problems with traditional music in Central Thailand were and how much overall appeal traditional music in Central Thailand had. A snowball sampling approach was used for unstructured interviews. Each respondent was asked to give names of individuals they felt could help with the investigation for further questioning. The focus group discussions were held with groups of six to eight key individuals to conclude the set of problems with Central Thai traditional music. One focus group discussion was held in each of the five provinces investigated and in attendance were musical group leaders, performers, musicians, community leaders, government representatives and related personnel. Data collected from documentary analysis was about the background of traditional music in Central Thailand, steps of performance, beliefs and customs, musical components and musical identity. Data collected from field research focused on current conditions of traditional music in Central Thailand, problems and modern appeal of the music.

The data was validated using triangulation methods. Investigator triangulation was used to validate data according to collector, methodological triangulation was used to validate data according to data capture technique and data triangulation was used to validate data according to location collected (Jantawanit, 2003; Denzin, 1970). Data was analyzed by analytic induction, SWOT analysis and typological analysis. Research results were presented as a descriptive analysis.

\section{Results}

\subsection{Current Problems with Traditional Music Performance in Central Thailand}

\subsubsection{Audience}

'The Traditional music of central Thailand is not popular because other excellent performances have spread [to Thailand].' (Kantapong Pengaram, 2012, interview)

'Traditional music in central Thailand has decreased in popularity because other performances have come to replace it.' (Kwanjit Sriprajan, 2012, interview)

'Normally I watch the television in my free time because it is convenient, free, does not require travel time and, importantly, traditional music is not performed regularly. I don't know when folk songs are being performed. Unless I pass them or someone comes to tell me, I don't have a chance to watch the performances.' (Mali Klinmala, 2012, interview)

'Nowadays, traditional performers cannot treat singing as their primary occupation because there are no stages to perform. The performers don't want a high income, just enough to get by. A real artist just wants to perform, a 
stage to show their ability and a place for the cultural heritage of their grandparents to be passed on.' (Samran Sukkam, 2012, interview)

In the past, viewing art performances was popular and audiences would watch the performances to see the postures, listen to the rhymes and admire the witty lyrics in traditional music shows. As media became more influential in everyday life, audience patterns changed and modern performances took the place of traditional entertainment in society. This is the reason for a decline in the popularity of traditional music and could lead to its disappearance, as has happened with prop gai music. In the past, employers held traditional music performance with great importance, especially the music of central Thailand. The likes of ee-saew, choi, pleng yey and ram tone were performed at every festival and annual event. This gave the performers a regular source of employment and there were not enough performers to meet the demand, putting existing performers in a strong position. However, nowadays the number of employment opportunities has been dramatically reduced. Primary factors for this are insufficient venues and high costs, which mean that the people are unable to employ performers as before. Additionally, the modern generations have less time to spend watching traditional performances because of an increased need to work and meet the financial demands of modern society. People are rarely free and required to work longer hours, meaning that they have little interest in folk songs. Only if it is absolutely necessary, will traditional music groups be employed to perform at local events, such as redemption ceremonies and funerals. Current traditional music performances last for one or two hours, a clear divergence from the past, when musical performances were played through the night. Additionally, the younger generation does not know what traditional music is or what the lyrics are like, which leads them to turn their attentions to the television or other media. This is how Western culture enters Thai society and causes audiences to lose interest in traditional entertainment. The majority of people consider traditional music of central Thailand to be outdated and boring, leaving audiences composed of the older generation.

\subsubsection{Social Conditions and the Surrounding Environment}

'...the arrival of modern media has caused the traditional music of central Thailand to adapt and modernize its performance, while incorporating stories from television shows as selling points to entertain the audiences...' (Prateep Onsalung, 2012, interview)

'With the arrival of modern media, traditional music groups have had to develop their performance model and include performance adaptations to appeal to and attract audiences.' (Chompoo Duangdet, 2012, interview)

'People of this generation don't really know about pleng yey or pleng choi. They watch the television and listen to the radio. The only people who love traditional music are old, and of those only a few fully appreciate it.' (Anon Petdon, 2012, interview)

'We must accept that we are part of an audience that loves modern media, whether it is television music CDs, the Internet or social networks. We like fun, temporary entertainment that is easier to access than traditional music, which is difficult to find and requires a dedicated audience.' (Saiyut Ponsen, 2012, interview).

Thai economy and society have changed. Trade has expanded and new technologies have been invented and adopted. The introduction of media has led to a growing choice of entertainment in the form of television, cinema, stage performance, modern music, karaoke, compact discs and the Internet. This has caused the waning popularity of traditional music. The traditional music performances that have not adapted their methods have declined. Those musical groups that have been able to adapt their content to fit modern trends are able to survive. The telephone, radio, CD, VCD and karaoke are forms of media that provide a platform for the adaptation of traditional music and the example has already been set by the adaptation of Thai country music, or look tung. Although folk songs are traditionally performed at local events, young people know less about it than the new global cultures that have entered society, such as K-pop and J-pop. Young people sing Korean and Japanese songs rather than the traditional Thai music and are more prepared to spend money downloading these songs and modern Thai pop than they are to watch free traditional music. Although young people cannot be forced to like and sing traditional music, they can be educated about its importance, the historical value it holds, the stories it tells and the lifestyle it reveals.

\subsubsection{Artists}

'...traditional music performances have changed from the past in order to survive and because there is a higher number of hiring managers it is necessary to adapt performances. Performers must know how to modernize their content to make it appropriate for the event at which they will perform. They must also convey the story and verse so that it appeals to the audience and adds value to their overall performance.' (Niyom Sariwong, 2012, interview) 
'Pleng ee-saew and pleng choi can still be played but there are no longer any groups. The cost is high and they cannot be taken care of. If you want to make a group, you must have a constant supply of work but the events are not all the time. Normally performers work as farmers and when there is an annual event they will come and perform. The income depends on how much the host is willing to give because the singers work through love of performing.' (Ku Taekkong, 2012, interview)

'This is a merit-making event and we employed the Mae Kwanjit music group at a special price. Normally you can't get this price. Other groups would get nowhere near it. It's a different price for different people.' (Pramahakao Nakwaro, 2012, interview)

'Most of the time I will be employed by Mae Kwanjit music group because they are famous and they are national musicians. When I have no work, I cannot live. We have to eat and spend. When I am employed by them I get more income and I don't have to invest anything. When I am free I look for work building or farming but, if Mae Kwanjit have work, they will call to use my services.' (Yaem Teunsuriya, 2012, interview)

Income was found to be an important survival factor of traditional Thai music in central Thailand. Given the difficulties of finding work in the aforementioned cultural climate, lead singers are turning to independent work, rather than establishing groups. This increases the variety of work they are able to perform, in turn raising their earning potential.

'...performances of traditional music in central Thailand are performances that require talent and training. Singers and performers of traditional music in central Thailand must be patient with their practice and love and be dedicated to practice.' (Yaem Teunsuriya, 2012, interview)

'Fine arts universities are institutions that have a responsibility in the inheritance of traditional music in central Thailand. For the spread of traditional music, they create traditional fine arts curriculums for their students. Each student must be able to sing traditional folk songs of central Thailand. As a part of Suphanburi, everyone must be able to ee-saew.' (Wanna Kaewkwang, 2012, interview)

'If you are not a pupil of Mae Kwanjit Sriprajan, you will not have an opportunity to sing ee-saew like this. She is dedicated to singing traditional central Thai music and takes care of her group. Before, she fainted during a traditional music performance, so I had to come and help her out but normally I have my own private work.' (Sutatip Taraporn, 2012, interview)

'People who sing and play here do so because they love it. The songs are difficult. You need wit and know how to memorize but Mae Kwanjit has passed it on so that her pupils know how. But people of this generation are not really interested any more.' (Teptai Lookangthong, 2012, interview)

'Really, the pupils who are still kids love to sing, dance and make music. They get dressed up, pretend to cry in the performance and love it. But I don't know if they'll be able to do it when they're older or if they'll be shy. This is what I'm scared of.' (Pantip Nakpleum, 2012, interview)

The experts and elders involved in traditional music will not worry about their musical education but there is no method of inheritance for future generations. It is difficult to practice and the younger generations are not interested in learning because it also comes with many customs and traditions, the stories are not entertaining and there seems no reason for it to continue. Practice requires patience and dedication, which causes younger people to become disheartened and discouraged. Young people have adopted modern Western culture and the value of traditional music has decreased. Even local institutions responsible for the inheritance of traditional folk songs do not fully commit. These factors, combined with the increasing age and decreasing health of experts, mean that the number of able traditional music performers is in decline. It is difficult to find people to carry on the traditions. Teachers only choose to educate family members and close friends and the government does not adequately sponsor or realize the importance of inheritance.

'Normally, news reporters will publicize things of interest to the population, especially event that the government asks to be publicized. News reporters are happy to publicize information that is brought to them but for local traditional music performances, it is still popular to advertize by word of mouth and there have never been any large advertising campaigns.' (Wai Denchai, 2012, interview)

The musical groups lack quality publicity. If there was increased publicity to inform the people, audiences would increase because it would attract more people to view the performances. Model performances held in the locality, educational institutions and in densely populated areas may help generate interest in the music. 


\subsubsection{Support}

'...participation and integration of the government, the private sector and the community are important in supporting the local ram tone music because, if not all departments realize the benefit of cooperation, it will be difficult. Sometimes, people involved will become discouraged but they must not give up because the benefit will be felt by our descendents.' (Prateep Onsalung, 2012, interview)

'...the budget from government institutions to sponsor pleng yey in the local area is almost non-existent but we are able to survive through our love of the music. But, if there was some sponsorship from the government, it would be a big encouragement, as now communities are forced to help themselves. We don't want our heritage to disappear from the community' (Prayong Kaewpradit, 2012, interview)

There is not as much support from related organizations as there should be because the importance of traditional music is not realized. There is no support from the community or large institutions to provide impulse to the performances. There is also very little information about traditional music in central Thailand and there is neither systematic work procedure nor adequate advertising. These are obstacles to local and national performances of traditional music. Government support of traditional knowledge related to central Thai music is not found in all areas. Even though the provincial culture offices do not have information related to traditional music performances, the culture of each region and each province should be treated as a part of national heritage that must be conserved and protected.

\subsection{The Appeal of Traditional Music in Central Thailand}

Appeal is the interest and attraction of the artists and performances to the audience. In central Thailand, there are different groups and artists that appeal to different audiences for different reasons. The Mae Kwanjit Sriprajan musical group is renowned for Mae Kwanjit Sriprajan's Ee-saew Performance (Figure 1). This is popular with audiences because Mae Kwanjit is a national performer in the branch of traditional music performing arts. In addition to being an expert performer, Mae Kwanjit is also known for passing on her skills to her pupils and apprentices by giving them stage time and opportunities at events that are not part of festivals and ceremonies. The music of Mae Kwanjit Sriprajan music group is melismatic, where one syllable of text is sung in more than one note. The star, Mae Kwanjit herself, will improvise her lyrics and performance to suit her audience. Importantly, Mae Kwanjit performs folk songs as they were intended.

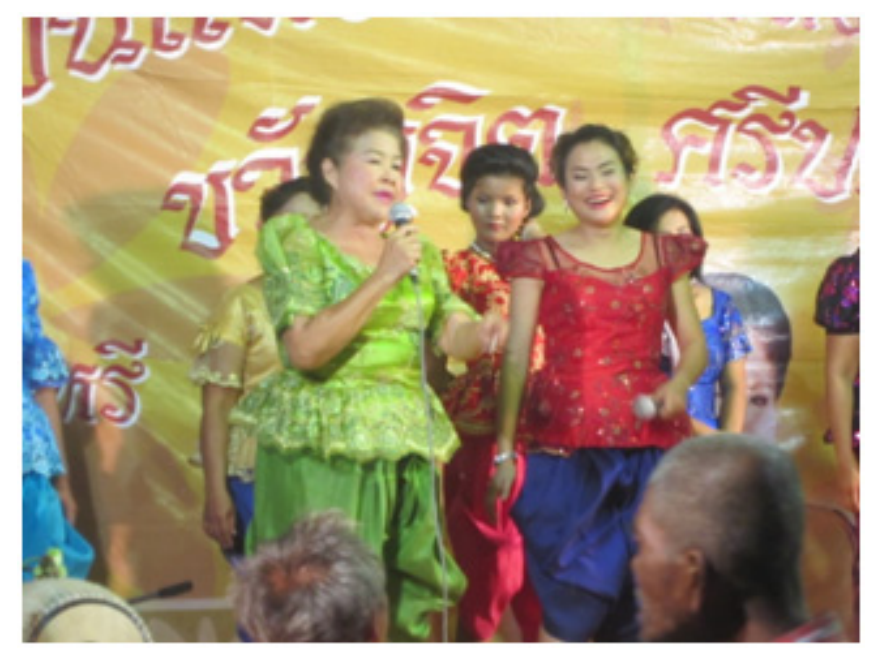

Figure 1. Mae Kwanjit Sriprajan performing on stage

The See Pee Nong music group has a truly traditional performance style and pedigree through inheritance from their grandparents. The group of mother and two daughters will improvise lyrics and dance styles so there is no need for memorization (Figure 2). At some events, the performances will consist of the mother scolding her children or using racy language to make them embarrassed. This is entertaining for the audiences because it requires visible wit and speed of thought (Samran Sukdam, 2012, interview). 


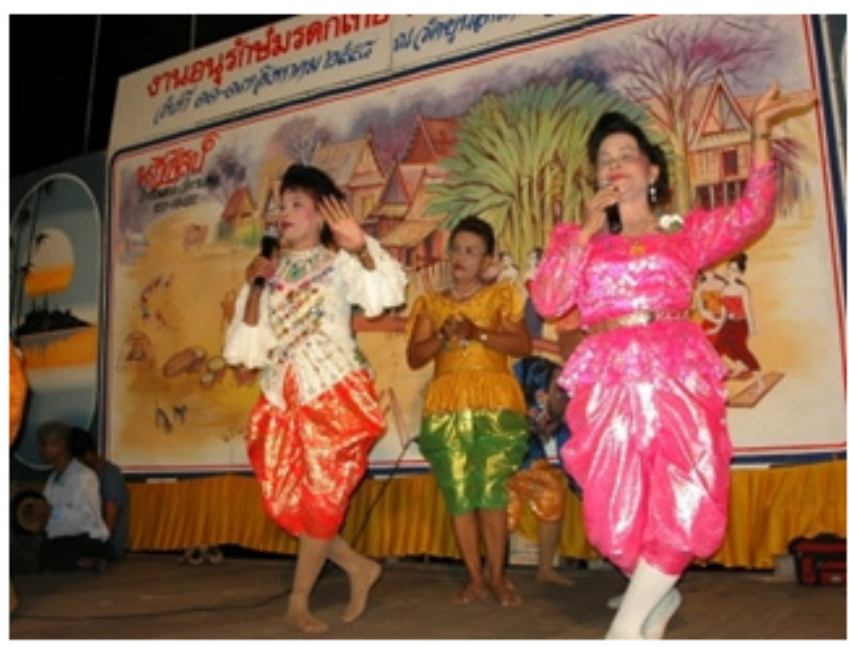

Figure 2. The See Pee Nong music group on stage

Ram Yey music group, under the administration organization of Nong Rong Sub-District is famous for its Ram Yey performance (Figure 3). The group was established after community cooperation to preserve traditional lifestyle. The appeal of the performances by this group stems from the traditional costumes, visible performer enthusiasm and traditional lifestyle portrayed. Additionally, the Yey music has no defined time limit so the performers may continue for as long as the audience is entertained. Instruments used are klong yao, pi, ching, chab, krab and mong. The appeal of the music is the ease with which people are entertained (Prayong Kaewpradit, 2012, interview).

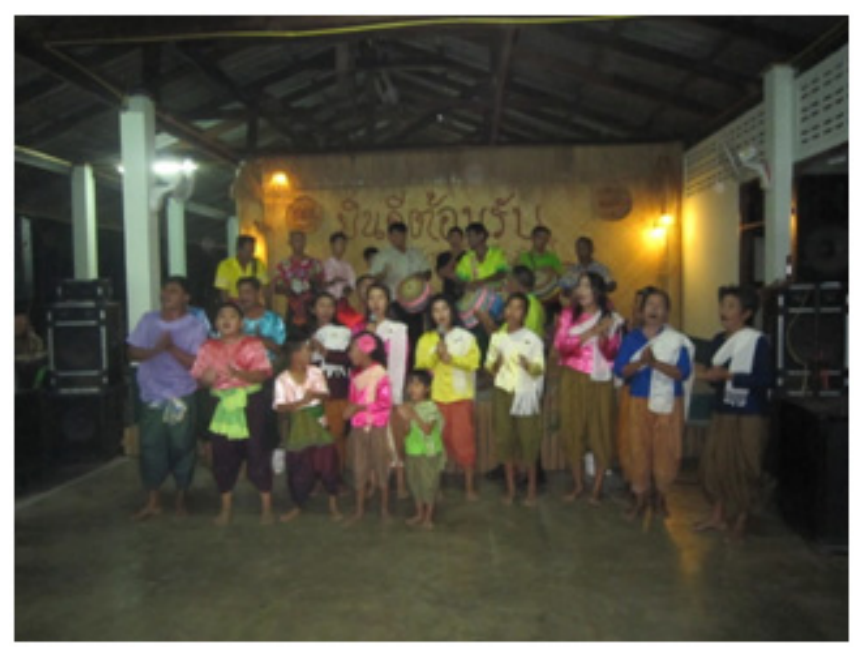

Figure 3. Ram Yey music group, under the administration organization of Nong Rong Sub-District

The Ram Tone Chao Thai Bueng music group has inherited its traditions from ancestors and maintains the original music and dance styles (Figure 4). The group earns a living in agriculture and comes together to perform the Ram Tone for entertainment. The incorporation of traditional music in the everyday lifestyle of the Ram Tone performers is important in attracting interest from outsiders (Prateep Onsalung, 2012, interview). 


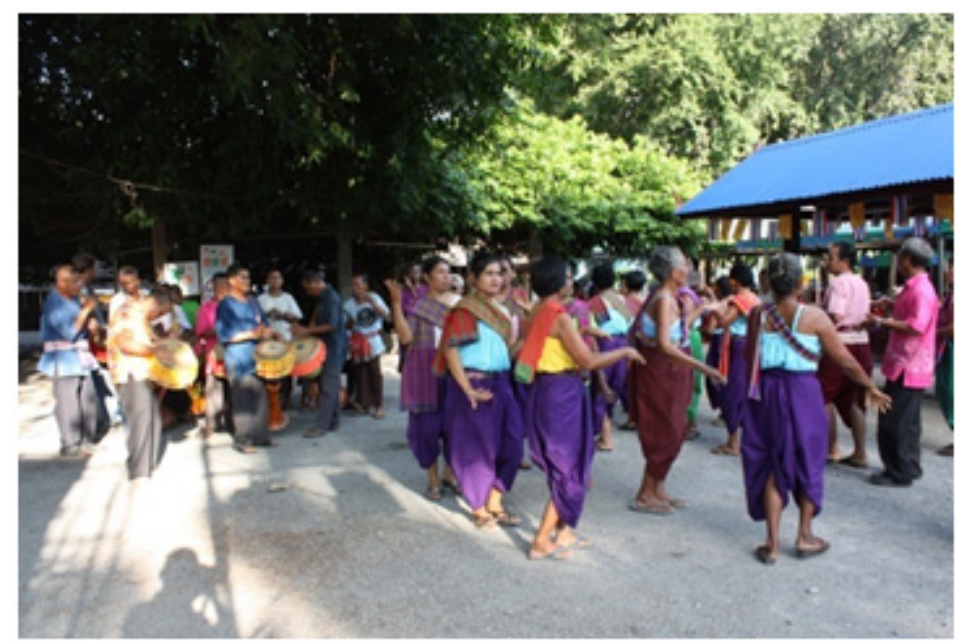

Figure 4. A Ram Tone performance by the Ram Tone Chao Thai Bueng music group

The Ram Tone music group from Wat Jakornsee School prevents traditional music from disappearing by incorporating it into the local school curriculum. The teachers hope that the children of the school may continue the traditions, so they teach the singing, dancing and music. The group includes children and members of the public. They will perform at school events but, thanks to the charm of the children, they are invited to perform at external functions. The group is financially sponsored by locals and is one example of traditional music being embraced by the younger generations (Pantip Nakpleum, 2012, interview).

\section{Discussion}

Thai folk songs are part of the local cultural heritage and can indicate the advancement or deterioration of society. Moreover, the music is a part of local identity and a reflection of the essence of life in central Thailand. Therefore, the music has an influence on the lifestyle of local people and, as a result affects national progress. At the same time, folk music was created to address social problems and respond to local needs. It unites communities and binds people to a unique identity. People of the same culture feel a sense of togetherness by creating their own identity and practices. This helps to define social behaviour and allows people to live together in harmony. These perceptions help to form the regulations of society and benefit the nation, particularly considering central Thailand's place at the centre of national policy-making, finance and administration. The importance of local culture was highlighted by Jaruwan Tammawat (s.d., p. 13), who found that culture solves human problems and responds to their needs, helps unite society, reflects national identity and strength, defines social behaviour and helps nations progress.

The age of globalization has dramatically affected Thai society, especially the people who have not kept up with the speed of change. From this study, three areas of influence can be determined:

1. Audiences are no longer impressed by the dance postures, rhymes and performance wit and turn to more impressive and convenient modes of entertainment. This is in keeping with the research results of Jintana Nuna (1991), who found that people now have a great choice of entertainment in the form of modern media. This is one reason for the decline of traditional music performances.

2. Social conditions and the surrounding environment have changed with the introduction of modern media. The economy and trade have expanded and technology is more prominent. Sutiwong Pongpaiboon (1982) concluded three consequences of these changes: academia has neglected Thailand in favour of Eurocentric and Americentric outlooks; technology has weakened work ethics and made time more precious for both performer and viewer; modern values have displaced community spirit and levels of cooperation and participation have suffered.

3. Artist problems include decreased earning potential, lack of inheritors and minimal interest from the younger generations. These problems can be categorized into three groups: problems created by the singers, problems created by the audience and problems created by the influence of foreign culture and society. Jintana Nuna (1991) also identified the narrow inheritance boundaries as limiting the chances of traditional music survival. 
One further problem discovered by this research was the lack of institutional support and sponsorship for traditional music.

The existence and adaptation of traditional music in central Thailand is dependent on the people and their behaviour in accepting the activities as part of their everyday lives. When the public adopts culture from outside, they must do so without detracting from the value of their own culture. It tends to be the case that a society gradually adopts foreign cultures that correspond to its own domestic culture. These new elements, which are 'borrowed' at first, soon become indistinguishable from the traditional customs (Pongsapich, 1994). Traditional music of central Thailand will survive if it meets the requirements of the local people and appeals to the community. This is in agreement with Pitaya Saihoo's theory (1980) that traditional culture and traditional performing arts take a typical form that incorporates the identities of different people in social groups. This is achieved by taking knowledge and understanding, creative ability, satisfaction and popularity to make collaborations that respond to social desires. The combination of these four elements is 'culture'. If the four elements come from different areas and mix as one culture, they may respond to the needs of people in each of those areas. As Boonyong Gettet (1993) concluded, culture is naturally inherited, especially in areas with a large communication network. Cultural exchange is not limited to the local area and this must be realised if the traditional music of Central Thailand is to expand its appeal and continue in the future.

\section{References}

Denzin, N. (1970). The Research Act in Sociology. Chicago: Aldine.

Detpimon, C. (1988). Study of shadow puppetry in Roi-Et Province [in Thai]. Unpublished masters thesis, Mahasarakham University, Mahasarakham.

Gettet, B. (1993). Research report into the ceremonies of the Phu Tai people: A case study of king, Nong Sung District, Mukdahan Province [in Thai]. Maha Sarakham: Mahasarakham University.

Jantawanit, S. (2003). Qualitative Research [in Thai]. Bangkok: Chulalongkorn University Press.

Loh-ngeun, C. (2009). Two-part singing of Central Thailand: Use of traditional knowledge in commercial performing arts [in Thai]. Maha Sarakham: Mahasarakham University.

Maijaroen, P. (2009). Conservation and development of a performance model for rod puppets in Central Thailand [in Thai]. unpublished doctoral thesis, Mahasarakham University, Mahasarakham.

Nawikamoon, A. (1984). Adapted music from outside this century (3rd ed.) [in Thai]. Bangkok: Tammasarn.

Nawikamoon, A., \& Poonpon, M. (1987). Panom Tuan traditional music [in Thai]. Bangkok: Thai Information Group.

Nuna, J. (1991). The declining role of ngeng-dan-yong [in Thai]. Unpublished doctoral dissertation. Chulalongkorn University, Bangkok.

Patarachai, S. (2000). Studies of traditional music [in Thai]. Bangkok: Chulalongkorn University Press.

Pongpaiboon, S. (1982). Procedures of traditional culture in the South [in Thai]. Songkhla: Sri Nakkarinwirot University.

Pongpaiboon, S. (1999). Sociological theories in line with Buddhism [in Thai]. Bangkok: Research sponsorship and funding office.

Pongsapich, A. (1994). Culture, religion and indigenous people: Humanities analysis of Thai society [in Thai]. Bangkok: Chulalongkorn University Press.

Saihoo, P. (1980). Social mechanisms [in Thai]. Bangkok: Chulalongkorn University.

Saprasert, S. (1999). The characteristics of traditional knowledge inheritance [in Thai]. Unpublished masters thesis, Mahidol University, Bangkok.

Srisantisuk, S., \& Buatuan, S. (1985). Social and cultural change in the Song Heng indigenous community of Kalasin Province [in Thai]. Khon Kaen: Khon Kaen University Press.

Subongkot, T., et al. (1983). Korat music [in Thai]. Nakhon Ratchasima: Siriaksorn.

Supanyot, B. (1992). Analysis of the ee-saew song of Suphanburi Province [in Thai]. Bangkok: Silpakorn University.

Sutchaya, S. (1982). Patipak music: Patipak lyrics of Thai people [in Thai]. Bangkok: Thammasat University Press. 
Tammawat, J. (1985). Research report into the role of Mor lam for Isan society in the middle of the century [in Thai]. Maha Sarakham: Research Institute of Northeastern Arts and Culture.

The Office of the National Education Commission. (1998). Evaluation report of the development plan for national education (vol. 7) [in Thai]. Bangkok: The Office of the National Education Commission

Tongbut, R. (1999). A study of the application of local wisdom to social studies instruction in secondary schools under the jurisdiction of the Department of General Education, Changwat Surin [in Thai]. Unpublished masters thesis, Khon Kaen University, Khon Kaen

Wangwan, S. (1998). Mor Lam Kok Kha Khao [in Thai]. Unpublished doctoral dissertation, Chulanlongkorn University, Bangkok

Wongtet, P. (1990). Traditional music [in Thai]. Silpakorn University Journal, 4(2), 22-25.

\section{Copyrights}

Copyright for this article is retained by the author(s), with first publication rights granted to the journal.

This is an open-access article distributed under the terms and conditions of the Creative Commons Attribution license (http://creativecommons.org/licenses/by/3.0/). 